\title{
Etica mediului în cursurile de Etică și integritate academică
}

\section{Dana PERNIU1 ${ }^{*}$, Cristina SALCĂ ROTARU1 ${ }^{1}$, Camelia DRĂGHICI ${ }^{1}$}

Citation: Perniu, D., Salcă Rotaru, C.M. \& Draghici, C. (2021). Etica mediului în cursurile de Etică și integritate academică. Etică și Deontologie. 1(2), 20-30

https://doi.org/10.52744/RED.2021.02.03

Publisher's Note: RED stays neutral with regard to jurisdictional claims in published maps and institutional affiliations.

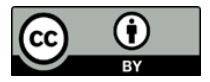

Copyright: (c) 2021 by the authors. Submitted for possible open access publication under the terms and conditions of the Creative Commons Attribution (CC BY) license

(https://creativecommons.org/ licenses/by/4.0/).
3 Universitatea Transilvania din Brașov; d.perniu@unitbv.ro, rotaruc@unitbv.ro c.draghici@unitbv.ro;

* Correspondence: d.perniu@unitbv.ro

Rezumat: Noile cursuri „Etică și integritate academică” introduse in curricula programelor de masterat completează procesul educațional cu dimensiunea sa axiologică. În cadrul acestor cursuri, studenții și în mod special studenții-ingineri sunt confruntați cu concepte precum morală, valori, bună conduită. Luând în considerare faptul că absolvenții de învățământ superior se vor încadra într-o societate care se dezvoltă în manieră durabilă, este din ce in ce mai pregnantă nevoia de identificare a unor punți care să facă legătura între formarea pur tehnică și aspectele etice ale dezvoltării tehnologice cu respectarea valorilor sociale și de mediu. Lucrarea de față prezintă un argument pentru predarea conceptului de etică a mediului în cadrul noilor cursuri de „Etică și integritate academica” la studenți din domeniul științelor inginerești, pentru a le crea oportunitatea de abordare a cuno;tin'elor de specialitate din multiple perspective de etică, socială și de mediu.

Cuvinte cheie: etică, mediu, curricula, dezvoltare durabilă, inginerie

Abstract: The new courses "Ethics and academic integrity" introduced in the curriculum of master's programs complete the educational process with its axiological dimension. In these courses, students and especially student-engineers are confronted with concepts such as morals, values, good conduct. Given the fact that higher education graduates will be part of a society that is developing in a sustainable way, there is an increasing need to identify bridges that link the purely technical training with the ethical aspects of technological development. respecting social and environmental values. This paper presents an argument for teaching the concept of environmental ethics in the new courses "Ethics and academic integrity" to students in the field of engineering, to create an opportunity for them to approach their knowledge from multiple ethical, social and environmental perspectives.

Keywords: ethics, environment, curriculum, sustainable development, engineering 


\section{Introducere}

În contextul crizei contemporane a mediului, care pune sub semnul întrebării posibilitatea viitoarelor generații de a-și asigura resursele necesare vieții de calitate, sistemul educațional joacă rolul cel mai important în formarea cunoștințelor, abilităților, atitudinilor necesare schimbărilor pentru tranziție către o dezvoltare socială, tehnologică, economică în manieră durabilă. Pentru realizarea acestei tranziții, este necesară formarea de persoane cu morală solidă, cu abilități creative înalte, care să fie capabile să abordeze probleme complexe, luând în considerare efectele sistemice, pe termen lung, care să contracareze criza contemporană (Nasibulina, 2015). Inginerii sunt cei care au un rol important in dezvoltarea și implementarea soluțiilor tehnice, adecvat și responsabil în raport cu această criză. Astfel, inginerul contemporan, în deciziile pe care le ia, nu se bazează doar pe cunoștințe strict tehnice, el adoptă abordări multidisciplinare, incluzând perspectiva etică și socială (van den Hoven, 2019).

Lucrarea de față aduce în discuție, fără pretenția exhaustivității, conceptul de etică a mediului ca subiect de introdus în curricula programelor de formare a viitorilor ingineri. Cursurile de Etică si integritate academica introduse in mod obligatoriu in curricula programelor de masterat începând cu anul universitar 2018/2019 (Ordin, 2018) aduc în atenția studenților masteranzi conceptul de etică în spațiul academic și reprezintă un cadru în care viitorii absolvenți pot fi introduși în domeniul complex al eticii mediului.

Lucrarea este structurată pe trei părți, care împreună constituie un argument pentru introducerea conceptului de etică a mediului în programul de formare a viitorilor ingineri, cel putin ca subiect în cadrul cursurilor de Etică si integritate academică. Prima parte prezintă succint exemple de probleme contemporane de mediu și conceptul de dezvoltare durabila, care constituie semnale de alarmă și care își pot găsi soluții prin implementarea dezvoltării socio-economice în manieră durabilă. Cea de a doua parte abordează spațiul universitar din perspectiva formării viitorilor absolvenți în raport cu dezvoltarea durabilă, iar partea a treia este dedicată conceptului de etică a mediului, cu multiplele sale dimensiuni. 


\section{Probleme contemporane de mediu și conceptul de dezvoltare durabilă}

Schimbările rapide la care este supusă planeta în ultimul secol și în special în ultima jumătate a secolului al XX-lea au afectat și afectează lumea în ansamblul ei, pe oricare dintre meridiane, la oricare scală spațială și în oricare dintre domeniile care susțin viața. Conform datelor de la Banca Mondială, populația globului în 2020 a ajuns la peste 7,7 miliarde locuitori, dintre care $56 \%$ sunt locuitori ai mediului urban (World Bank, 2020). Ca rezultat, creșterea economică de peste 12 ori comparativ cu anul 1950, este coroborată cu o creștere de peste 5 ori a cantității de energie consumată, și cu o creștere masivă a utilizării resurselor naturale (SOER, 2020). Pe de altă parte, aproximativ 75\% din mediul terestru și 40\% din mediul marin sunt alterate în mod sever (SOER, 2020). Datorită calității precare a mediului, Organizația Mondială a Sănătății a estimat pentru anul 2012, un număr de 12,6 milioane de decese, reprezentând $23 \%$ din totalul deceselor pe plan mondial, datorate poluării aerului de interior și exterior și calității necorespunzătoare a apei (Prüss-Ustün et al., 2016).

Conceptul de dezvoltare durabilă, așa cum a fost definit în cadrul Conferinței Naţiunilor Unite de la Stockholm, 1987 prevede o dezvoltare care să satisfacă nevoile generației actuale, fără a compromite posibilitatea viitoarelor generații de a-și satisface propriile necesități. Conceptul presupune o etică între generații, presupune viziunea de dezvoltare, de bunăstare, dar și atrage atenția asupra riscului datorat limitelor planetei. Dezvoltarea durabilă este un concept generos, larg, complex, adesea denumit concept „umbrelă”. Este un concept provocator și controversat (Verma and Raghubanshi, 2018), având mai mult caracter normativ decât o definire concretă (Turcu, 2013), dar creionează cadrul de acțiune la diferite niveluri ale sistemului socio-economic.

Conceptul este cunoscut în mod tradițional ca integrând trei piloni care vizează (i) dezvoltarea socială, (ii) creșterea economică, ambele fără a prejudicia (iii) calitatea mediului. Literatura de specialitate (Spangenberg, 2004, Turcu, 2013) menționează necesitatea introducerii celui de al patrulea element, cel instituțional prin care se asigură formularea politicilor și strategiilor în domeniu.

Sfârșitul de secol XX și începutul celui de al XXI-lea, au marcat, dincolo de dezvoltarea rapidă și accelerată în plan socio-economic coroborată cu deteriorarea calității mediului, numeroase eforturi de elaborare de politici și programe de acțiune pentru dezvoltarea durabilă. Aplicarea acestui concept presupune modificări 
numeroase și complexe, la toate nivelurile sistemului socio-economic, modificări care se produc atât la nivel fizic, cât și conceptual.

Unul dintre cele mai răsunătoare exemple este Summitului Națiunilor Unite, din septembrie 2015, în cadrul căruia a fost adoptată Agenda 2030 pentru dezvoltare durabilă, program de acțiune globală cu caracter universal, care promovează echilibrul între cele trei dimensiuni ale dezvoltării durabile - economic, social și de mediu (MAE, 2021). Agenda cuprinde 17 Obiective de Dezvoltare Durabilă (Obiective Globale), prin care lumea, în ansamblul ei, se angajează la eradicarea sărăciei extreme, combaterea inegalităților și a injustiției, stabilitate regională și globală, protejarea planetei până în anul 2030, Figura 1.

\section{SUSTAINABLE DEVELOPMENT}
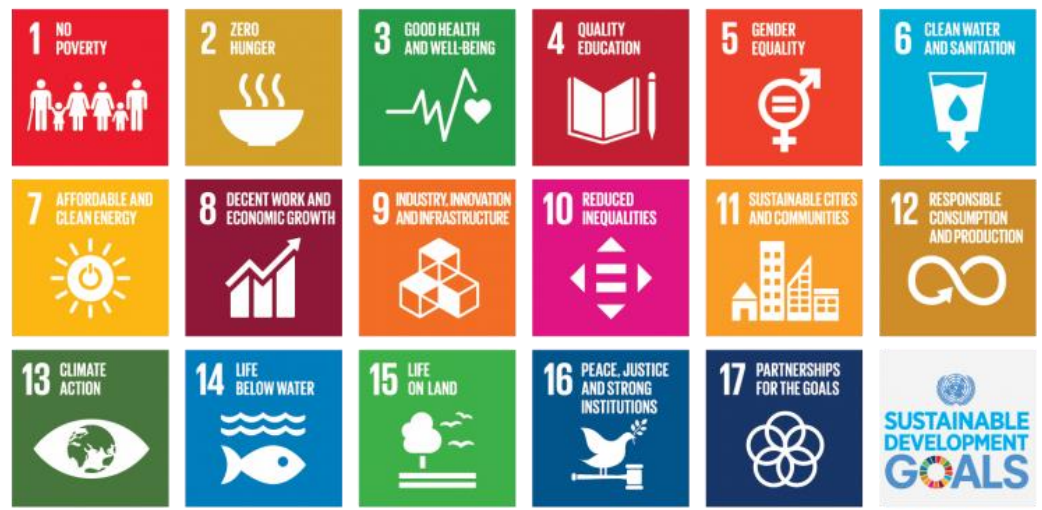

(3)

SUSTAINABLE

DEVELOPMENT

Figura 1: Țintele dezvoltării durabile

Sursa: https://www.un.org/sustainabledevelopment/sustainable-development-goals/

În prezentare succintă, țintele dezvoltării durabile se transpun în (UN 2030 Agenda):

1. Fără sărăcie - Eradicarea sărăciei în toate formele sale și în orice context;

2. Foamete "zero" - Eradicarea foametei, asigurarea securității alimentare, îmbunătățirea nutriției și promovarea unei agriculturi durabile;

3. Sănătate și bunăstare - Asigurarea unei vieți sănătoase și promovarea bunăstării tuturor la orice vârstă;

4. Educație de calitate - Garantarea unei educații de calitate şi promovarea oportunităților de învățare de-a lungul vieții pentru toți; 
5. Egalitate de gen - Realizarea egalității de gen şi împuternicirea tuturor femeilor şi a fetelor;

6. Apă curată şi sanitaţie - Asigurarea disponibilității şi managementului durabil al apei şi sanitație pentru toți;

7. Energie curată şi la preţuri accesibile - Asigurarea accesului tuturor la energie la prețuri accesibile, într-un mod sigur, durabil și modern;

8. Muncă decentă şi creștere economică - Promovarea unei creșteri economice susținute, deschise tuturor şi durabile, a ocupării depline şi productive a forței de muncă şi a unei munci decente pentru toți;

9. Industrie, inovaţie şi infrastructură - Construirea unor infrastructuri rezistente, promovarea industrializării durabile şi încurajarea inovaţiei;

10. Inegalităţi reduse - Reducerea inegalităților în interiorul țărilor şi de la o țară la alta;

11. Oraşe şi comunităţi durabile - Dezvoltarea oraşelor şi a aşezărilor umane pentru ca ele să fie deschise tuturor, sigure, reziliente şi durabile;

12. Consum şi producţie responsabile - Asigurarea unor tipare de consum şi producție durabile;

13. Acţiune climatică - Luarea unor măsuri urgente de combatere a schimbărilor climatice şi a impactului lor;

14. Viaţa acvatică - Conservarea şi utilizarea durabilă a oceanelor, mărilor şi a resurselor marine pentru o dezvoltare durabilă;

15. Viaţa terestră - Protejarea, restaurarea şi promovarea utilizării durabile a ecosistemelor terestre, gestionarea durabilă a pădurilor, combaterea deșertificării, stoparea şi repararea degradării solului și stoparea pierderilor de biodiversitate;

16. Pace, justiţie şi instituţii eficiente - Promovarea unor societăţi pașnice și incluzive pentru o dezvoltare durabilă, a accesului la justiție pentru toți şi crearea unor instituții eficiente, responsabile şi incluzive la toate nivelurile;

17. Parteneriate pentru realizarea obiectivelor - Consolidarea mijloacelor de implementare și revitalizarea parteneriatului global pentru dezvoltare durabilă.

În contextul actualului studiu, importanța studiului eticii de mediu își găsește relevanță în primul rând în cadrul obiectivului 4 - Educație de calitate, studenţii 
programelor de studii de inginerie acționând, prin intermediul profesiilor lor, în primul rând zona obiectivelor: 6 - Apă curată şi sanitație, 7 - Energie curată şi la prețuri accesibile, 9 - Industrie, inovație şi infrastructură, 11 - Oraşe şi comunități durabile, 12 - Consum şi producție responsabile și 13 - Acțiune climatică.

România, ca stat membru ONU, precum și ca membru al Uniunii Europene este angajată în formularea de politici și în acțiuni care conduc spre îndeplinirea obiectivelor dezvoltării durabile. La nivel național a fost formulată Strategia națională pentru dezvoltarea durabilă a României 2030 care susține dezvoltarea României pe cei trei piloni economic-social și de mediu, "fiind orientată către cetățean și centrată pe inovație, optimism, reziliență și încrederea că statul servește nevoile fiecărui cetățean într-un mod echitabil, eficient și într-un mediu curat, în mod echilibrat și integrat" (MAE, 2021).

\section{Universitățile și dezvoltarea durabilă}

Universitatea, ca spațiu în care cunoașterea este creată, aplicată, diseminată, are rol cheie in susținerea tranziției către durabilitate, constituind un agent important al schimbării (Chankseliani and McCowan, 2021). Misiunea unei universități, stipulată în codul de etică, cuprinde asumarea angajamentelor pe care aceasta și le ia în raport cu procesele de bază, de formare a resursei umane, de cercetare și inovare pe care le derulează în contextul socio-economic specific. Există universități în care, explicit sau sugerat, au asumate angajamente în raport cu dezvoltarea durabilă sau chiar cu obiectivele dezvoltării durabile (Mion et al, 2019, Romero, et al, 2020). În plan educațional, este declarată pregătirea studenților pentru a crea o societate (mai) durabilă, prin cunoștințele, deprinderile, atitudinile pe care aceștia și le construiesc pe parcursul studiilor, pentru a fi capabili să ia decizii informate, să conducă companii/ organizații (mai) responsabil în raport cu mediul natural sau construit. Prin activitățile de cercetare-inovare la nivel fundamental sau aplicat, în spațiul universitar se generează noi cunoștințe în varii domenii științifice sau umaniste, urmărind direct sau indirect cunoașterea din ce în ce mai profundă a vieții, a sistemului planetar la diferitele sale niveluri, a componentelor biotice, abiotice, tehnologice și a relațiilor dintre acestea. În universități este promovată paradigma dezvoltării durabile, iar obiectivele dezvoltării durabile incluse în declarațiile de natura etică și implementate în acțiuni concrete, coerente și conștiente, înscriu 
rezultatele învățării studenților în planul valorilor individuale și organizaționale (Mion et al, 2019, Romero et al, 2020).

În ceea ce privește învățământul superior tehnic, formarea viitorilor ingineri ia, sau ar trebui să ia în considerare aspectele etice ale profesiunii. În practicarea meseriei, inginerul este confruntat, de exemplu cu reflecții de natură etică în raport cu diverse aspecte normative, precum și cu asumări de responsabilitate în cursul rezolvării problemelor de natură tehnică (Grunwald, 2001). Astfel, curricula în domeniul științelor inginerești, ar trebui să integreze aspecte etice, științifice și cele de cooperare pentru a pregăti ingineri care să răspundă adecvat și responsabil la cerințele impuse de scopurile dezvoltării durabile. Inginerul nu mai poate aborda o singură problemă, izolată, căci eventuala soluție poate conduce la perturbări într-o altă zonă. El trebuie să aibă capacitatea de a adopta o perspectivă largă, multidisciplinară, incluzând atât aspectele etice cât și pe cele sociale (van den Hoven, 2019).

În învățământul superior tehnic românesc, profilul absolventului este descris prin rezultatele învățării cuprinse în opt arii:

1. cunoaștere și înțelegere,

2. analiză inginerească,

3. proiectare inginerească,

4. cercetare,

5. practică inginerească,

6. formare a opiniilor,

7. comunicare și muncă în echipă,

8. formare continuă (Standarde, 2016).

Procesul de învățământ vizează în mod special dimensiunea cognitivă prin formarea cunoștințelor și deprinderilor specifice studiilor inginerești, iar paradigma învățământului centrat pe student se rezumă, adesea la „ce știu” și „ce știu să facă” studenții/absolvenții. Noile cursuri Etică și integritate academică introduse in curricula programelor de masterat (Ordin, 2018) completează procesul educaţional cu dimensiunea sa axiologică. În cadrul acestor cursuri, studenții și în mod special studenții-ingineri sunt confruntați cu concepte precum morală, valori, bună conduită. În acest context, se pune problema abordărilor de natură etică specifice ingineriei, iar etica mediului, vizând dezvoltarea socio-tehnico-economică durabilă, poate fi un subiect de sine stătător. Studenții pot avea astfel oportunitatea formării unor 
capacități de abordare multidisciplinară a subiectelor din domeniul de studii, luând în considerare faptul că ei se vor integra într-o societate în care dezvoltarea durabilă este un nou mod de viață.

\section{Etica mediului}

În câmpul cercetărilor filosofice, etica mediului a apărut ca domeniul distinct, concentrându-se asupra protecției mediului, ceea ce impune reconsiderarea valorilor moderne, vizând acțiunea "corectă" în raport cu mediul în manieră comprehensivă, în numeroase aspecte ale vieții contemporane (Stoenescu, 2016). Lumea materială non-umană este abordată ca valoare intrinsecă, având propriul drept la existență, impunând obligații morale și juridice. Dezvoltarea socio-economică, direcționată de obiectivele dezvoltării durabile are o pregnantă componentă etică prin reglementarea relației om-tehnologie-natură.

În etică se disting, în sens larg două abordări: teleologică și deontologică (Keitsch, 2018). Eticile telologice interpretează binele ca scop final. Aceasta presupune cunoașterea regulilor de acțiune, conștientizarea consecințelor anumitor comportamente, libertatea de alegere conștientă a unui anumit mod de acțiune. La nivel individual se așteaptă comportamente favorabile protejării mediului, ceea ce implică atenție asupra modului în care comportamentelele sunt generate, gestionate și conduse de atitudini favorabile. În campul eticilor teleologice sunt cuprinse:

- utilitarismul - în care mediul este înțeles ca sursa inepuizabilă de resurse pentru satisfacerea nevoilor umanității;

- etica responsabilităţii - din perspectiva căreia omul, pentru a-și susține viața, viitorul, își asumă responsabilitatea de a fi în viață și de a conserva natura, ceea ce înseamnă că „averea omului” și „averea naturii” sunt interconectate (Mantatov and Mantatova, 2015);

- etica virtuții - din perspectiva căreia acțiunile care păstrează calitatea mediului aparțin unor persoane virtuoase, iar această calitate este corelată cu cunoașterea (Stoenescu, 2016).

Etica deontologică, sau etica datoriei, se referă la motivația morală și la regulile specifice, independente de consecinețele acțiunii. Este o etică care promovează ideea datoriei, a obligației, a trebuinței (Georgescu, 2021). Conceptul dezvoltării durabile 
este ilustrativ din punctul de vedere al datoriei generației acuale de a nu periclita posibilitățile generațiilor viitoare de a-și satisface propriile nevoi.

Etica mediului presupune o abordare holistă a înțelegerii acțiunilor umane și a consecințelor acestora asupra mediului, coroborând abordările antropocentrică, ecocentrică și teocentrică.

În abordare antropocentrică, acțiunile umane constituie cauza principală a crizei de mediu, fiind compromisă conservarea capitalului natural, în concepție utilitaristă, mediul fiind sursa inepuizabilă de resurse. În compensație, la nivel filozofic s-a dezvoltat econcentrismul, în care elementul natural este primordial (Liu et al, 2016). Etica mediului oferă perspectiva relațională, prin abordarea integrată a interacțiunii om-mediu astfel încât, de exemplu, decizii luate în managementul resurselor naturale consideră aspectele sociale, ecologice conectate într-un anumit context, în mod complex, dar adesea incert (de Wet and Oghenekaro, 2019) Abordarea etică aduce în discuție „administrarea mediului” privită ca grijă pentru un lucru particular, în care entitățile au încredere (natura, societatea, generaţiile următoare, etc). Se realizează astfel tranziţia de la antropocentrism către ecocentrism, iar omul devine partea responsabilă a administrării mediului (Liu et al., 2016). Se induce și etica grijii prin care este introdusă ideea de a face totul pentru a menține, continua, repara, „lumea” noastră încât să (îi) asigurăm viața cât de mult este posibil (Pla-Julian and Guevara, 2019). Grija și responsabilitatea se aplică la toate nivelurile de dezvoltare socio-economică: micro (individual), mezo (instituție, comunitate, zonă urbană), macro (global).

Relația om-mediu este prezentă și în sfera religioasă. În Cartea Sfântă, viziunea creștină asupra valorizării lumii naturale este reliefată în Geneză - Facerea, 1, 28: „Lumea a fost creată de Dumnezeu pentru oameni, iar omul a fost numit stăpân peste tot pământul" (Stoenescu, 2016). Etica mediului este abordată în mesajele clerice, la cel mai înalt nivel. Astfel, în encilcica Laudatio Si' (2015), Papa Francisc a transmis mesaj de ocrotire a pamântului „casa noastră comună” și a recomandat acțiuni urgente, riguroase, însoțite de o gândire profudă, de grijă față de mediu, menționând necesitatea dezvoltării de noi atitudini și stiluri de viață pentru a nu distruge pământul și însăși specia umană (Sanchez Garcia and Diez Sanz, 2018). Din partea Bisericii Ortodoxe, Patriarhul Bartolomeu, în mesajul cu ocazia zilei mediului 2018, atrage atenția asupra faptului că lumea trebuie înțeleasă ca o „casă” de care omul 
trebuie să aibă grijă, iar viitorul aparține unei culturi a solidarității și a respectului pentru integritatea Creației (Iftimiu, 2018).

În contextul conceptului de dezvoltare durabilă, etica mediului presupune deci o nouă abordare a temporalității și spațialității, vizează efectele pe termen lung ale acțiunilor umane, cu grija și resposnabilitate pentru respectarea dreptului la viață și la satisfacerea nevoilor în interiorul aceleiași generații și pentru generațiile următoare.

\section{Concluzii}

Societatea contemporană se confruntă cu o profundă criză a mediului, cu efecte la nivel individual, de comunitate, sau global. Pentru a face față acestei crize, la nivel global în contextul conceptului de dezvoltare durabilă s-au adoptat obiectivele dezvoltării durabile din care sunt derivate strategii de acțiune la diferite niveluri ale sistemului socio-economic. Implementarea acestor obiective necesită înțelegerea complexității lor, a interdependențelor dintre acestea.

Lucrarea de față a evidențiat rolul cheie ce revine universităților care formează noile generații de specialiști care să fie capabili să contribuie, prin acțiuni specifice la promovarea obiectivelor dezvoltării durabile, să își formeze opinii argumentate, să ia decizii informate, să abordeze problemele care se cer a fi rezolvate din multiple perspective, care coroborează dimensiunile științifică, socială și etică.

S-au adus argumente care justifică faptul că etica mediului poate fi privită ca fiind un unghi de abordare a proiectelor și problemelor din sfera ingineriei într-o societate care se dezvoltă în manieră durabilă. Astfel se creează oportunitatea viitorilor specialiști de a integra cunoștințele specifice domeniului de studii într-un context amplu, care coroborează aspectele tehnice cu cele de mediu și cu cele sociale.

Coborând „la firul ierbii”, se propune ca în cadrul cursurilor de Etică și integritate academică adresate studenților din domeniul științelor inginerești să se creeze oportunități formative de dezvoltare a unor capacități de abordare a subiectelor specifice domeniului de studii din perspectiva eticii mediului.

\section{Referințe}

Chankseliani, M., McCowan, T., (2021), Higher education and the Sustainable Development Goals, Higher Education, 81, 1-8.

Georgescu, T. (2021), „Deontologie” și „etică” - o perspectivă etimologică, în: Colang, G., (ed) Deontologie academică și etică aplicată, București, Editura Eikon. 
Grunwald, A., (2001), The Application of Ethics to Engineering and the Engineer's Moral Responsibility: Perspectives for a reserach Agenda, Science and Engineering Ethics, 7, 415-428.

Iftimiu A., Patriarhul Ecumenic în mesajul de ziua protecției mediului înconjurător: Viața Bisericii Ortodoxe este o ecologie aplicată, 29.08.2018, https://basilica.ro/patriarhul-ecumenic-inmesajul-de-ziua-protectiei

van den Hoven, J., (2019), Ethics and the UN sustainable Development Goals: The Case for Comprehensive Engineering, Science and Engineering Ethics, 25, 1789 - 1797.

Keitsch, M., (2018), Structuring Ethical Interpretation of the Sustainable Development Goals Concepts, Implications and Porgress, Sustainability, 10, 829.

Liu, X., Liu G., Yang Z., Chen B., Ulgiati S., (2016), Comparing national environmental and economic performances through emergy sustainability indicators: Moving enviornmental ethics beyound anthropocentrism toward ecocentrism, Renewable and Sustainable Energy Reviews, 58, 1532-1542.

MAE, Agenda 2030 pentru dezvoltare durabilă, (2021) https://www.mae.ro/node/35919.

Mantatov, V., Mantatova, L., (2015) Philosophical Underpinnings of Environmental Ethics: Theory of Responsibility by Hans Jonas, Procedia - Social and Behavioral Sciences 214, 1055-1061.

Mion G., Broglia A., Bonfanti A., (2019), Do Codes of Ethics Reveal a University's Commitment to Sustainable Development? Evidence from Italy, Sustainability, 11, (2015) 1134.

Nasibulina, A., (2015), Education for Sustainable Development and Environmental Ethics, Procedia - Social and Behavioral Sciences 214 (2015) 1077 - 1082.

Ordin. (2018). Ordinul nr 3131 din 30 ianuarie 2018, privind includerea în planurile de învățământ, pentru toate programele de studii universitare organizate în instituțiile de învățământ superior din sistemul național de învățământ, a cursurilor de etică şi integritate academică, publicat în M.O. nr. 140 din 14 februarie 2018.

Pla-Julian I., Guevara S., (2019) Is circular economy the key to transitioning towards sustainable development? Challanges form the perspective of care ethics, Futures, 105, 62-77.

Prüss-Ustün A., Wolf J., Corvalan C., Bos R., Neira M., (2016), Preventing disease through healthy environments - a global assessment of the burden disease from environmental risks, World Health Organization, https://www.who.int/quantifying_ehimpacts/publications/ preventing-disease/en/

Romero, S., Alaez, M., Amo, D., Fonseca, D., (2020), Systematic Review of How Engineering Schools around World Are deploying the 2030 Agenda, Sustainability, 12, 5035.

Sanchez Garcia, J.L., Diez Sanz, J.M., (2018), Climate change, ethics, and sustainability: An Innovative approach, Journal of Innovation \& Knowledge, 3, 70 - 75.

SOER, The European environment - state and outlook 2020: knowledge for transition to a sustainable Europe, https://www.eea.europa.eu/soer

Spangenberg J., (2004), Reconciling sustainability and growth: criteria, indicators, policies, Sustainable Development 12, 74-86.

Standarde. (2016). Standarde și linii directoare pentru certificarea EUR-ACE® a programelor de studii din domeniul fundamental științe inginerești, 2016, https://www.aracis.ro

Stoenescu, C., (2016), Etica Mediului - Argumente rezonabile și întâmpinări critice, Iași, Institutul European.

Turcu C., (2013) Re-thinking sustainability indicators: local perspectives of urban sustainability, Journal of Environmental Planning and Management, 56, 695-719.

UN 2030 Agenda. (2015). Transforming our world: the 2030 Agenda for Sustainable Development. https://sdgs.un.org/2030agenda

Verma P., Raghubanshi A.S., (2018) Urban sustainability indicators: Challenges and opportunities, Ecological Indicators, 93, 282-291.

de Wet, C., Odume Oghenekaro N., (2019) Developing sytemic-relational approach to environmental ethics in water resource management, Environmental Science and Policy, 93, 139-145.

World Bank Open Data, https://data.worldbank.org/indicator 